\title{
A CASE STUDY OF DAMAGE ON MASONRY BUILDINGS PRODUCED BY TUNNELING INDUCED SETTLEMENTS REVIEWED - MAY 2012
}

\author{
Carles Camós $(*)$, Climent Molins, Oriol Arnau
}

Departament d'Enginyeria de la Construcció

Universitat Politècnica de Catalunya (UPC), Jordi Girona 1-3, 08034 Barcelona

$\left({ }^{*}\right)$ Contact: carles.camos-andreu@upc.edu, (+34) 934010795

\begin{abstract}
This paper analyzes the structural response of a group of masonry buildings subjected to real ground movements experienced during the construction of the L9 Metro tunnel in Barcelona, bored by a Tunnel Boring Machine (TBM) - Earth Pressure Balance Machine (EPB). The studied one-storey small dwellings represent a common building typology frequently used in those days in Barcelona's outskirts (more than 1000 were erected). Real settlement profiles are compared with the ones provided by empirical methods, which estimate the shape and the area of the trough according to the ground properties and the volume loss (inherent to the tunneling construction method). The first aim of the paper is to evaluate the effectiveness of two techniques used to predict damages in buildings resulting from tunneling subsidence: 1) the 'equivalent beam' and its subsequent refinements, and 2) the appliance of a non-linear Finite Element macro-model. The real structural damage presented in the buildings is compared with the predictions given by this two methods. Main model parameters have been determined by means of characterization experiments developed on the site and in the laboratory, thus giving a much higher significance to the analysis. The obtained predictions present a high correspondence with the actual damage registered, particularly in crack pattern and in crack widths.
\end{abstract}

Key words

Tunneling, settlements, building, structural damage, equivalent beam, numerical simulation

\section{Introduction}

Underground constructions, such as tunnels and excavations, are essential to integrate transportation infrastructures in our cities. Tunneling always produces soil settlements that can affect the architectural heritage along its track. The significance of the ground movements is closely related to the diameter of the tunnel section, the tunnel depth and the particular conditions of the surrounding ground (bearing capacity of materials, presence of groundwater and the construction method employed). The prediction of the value and location of settlements is an essential task of the design process in order to set out the proper instrumentation to control the surface settlements evolution and thus, to minimize the damage likely to occur in buildings (Standing, 2008).

The classical methodology of subsidence prediction is still widely used. It is based on empirical approaches that describe the settlement profile transverse to the tunnel axis by means of Gaussian shape curves (Peck, 1969; Attewell et al., 1986; Rankin, 1988) (Figure 1). Apart from settlements, tunneling also produces horizontal ground displacements, which can induce tensile and compressive strains in building foundations.

Once the foreseeable ground movements are determined in greenfield conditions (meaning no presence of buildings and pavements), the determination of damage on buildings is commonly estimated by using an equivalent weightless elastic beam, which models the walls of the building assuming that they conform perfectly to the settlement shape (Burland \& Wroth, 1974). The maximum tensile strains in this beam are calculated according to the expressions of the deflection in a centrally loaded beam, having both bending and shear stiffness (Timoshenko, 1957). In addition, the influence of horizontal tensile strain coming from ground can be introduced by superposition according to the approach of Boscardin \& Cording (1989). 


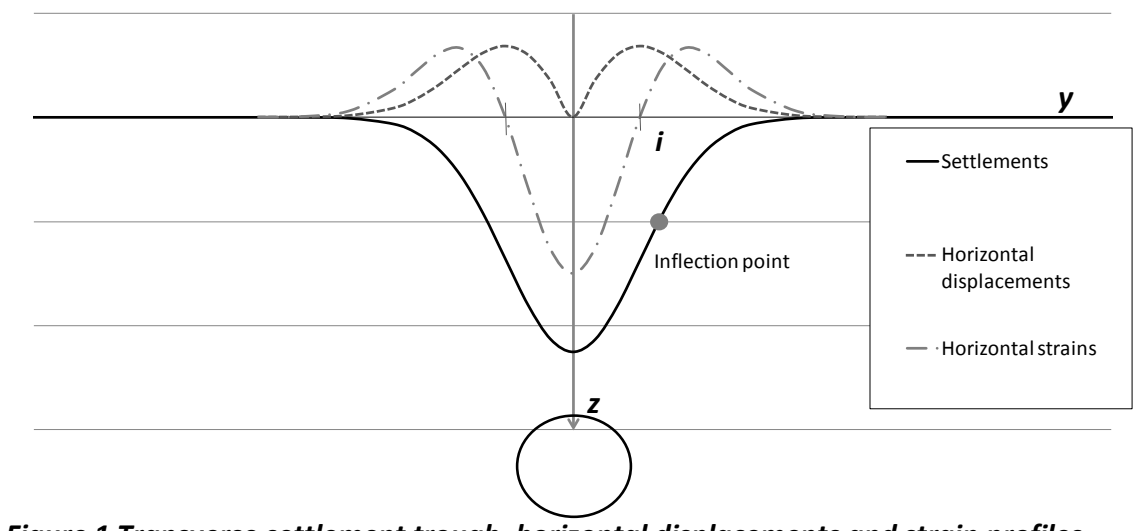

Figure 1 Transverse settlement trough, horizontal displacements and strain profiles

The maximum strains obtained in the equivalent beam are used to determine the category of damage associated with masonry buildings (Burland et al., 1977). This classification gives the description of the typical damage likely to occur in terms of type of affection, onset of cracking, typical crack width and ease of repair (see Appendix A).

This methodology has been mainly used in preliminary phases of design and quite often the results obtained are rather conservative. In the majority of cases, the actual damage was less than the predicted damage based on this methodology. The reason for this is that, in calculating the tensile strains, the building is assumed to have no stiffness so that it conforms to the 'greenfield site' subsidence trough (Burland, 2008). For this reason, Potts \& Addenbrooke (1997) assessed the influence of the inherent stiffness of a building and introduced a set of factors in order to take into account the interaction with the supporting ground and hence, obtaining apparently more reliable strains within a building.

Nowadays, the equivalent beam approach represents a first stage methodology commonly used in tunnel design to establish which buildings may require a detailed evaluation due to their sensitivity to tunneling induced settlements. Commonly, when drilling a tunnel, many recognition campaigns are carried out to distinguish whether possible structural pathologies can be related to tunneling, thus creating huge databases of information. Additionally, the machine operational parameters recorded by different sensors installed in the shield, give a real-time control of the construction works and allow the suitability assessment of these classical approaches in damage prediction.

The equivalent beam approach is based on a series of hypotheses that facilitate its common application but can turn the method somewhat uncertain (Gesto \& Gens, 2008). Also, very few examples of numerical damage prediction can be found in the literature (Lourenço, 1996; Burd et al., 2000; Rots et al., 2005). However, back analyses that allow the appropriate assessment of such methods are rather scarce in literature. For this reason, it is of major importance to check the reliability of these approaches by comparing their predictions with real cases of damage occurred due to tunneling.

The present paper focuses on the structural response of a group of masonry buildings subjected to tunneling subsidence experienced during the construction of the L9 Metro tunnel in the neighborhood of Bon Pastor (Barcelona). The one-storey small dwellings erected (more than 1000), represent a common building typology frequently used in those days in Barcelona's outskirts. The analysis is carried out in the facade of a group of six dwellings located at Sanet street (Figure 2). This particular set of buildings was selected due to its proximity to the tunnel track and the large settlements occurred during the construction of the Metro tunnel. Because of the importance of these buildings for the history of the city, a sample will be preserved.

Initially, the real settlement profile is compared with the results provided by the analytical expressions of the state of the art. The equivalent beam method and its subsequent refinements are then applied to predict the expected damages in the dwellings, which precision is stated by comparing with the real damage surveys. However, techniques like the 'equivalent beam' can give only a broad classification of damage which can be useful only for preliminary assessment. When a more detailed evaluation is 
pretended, numerical simulation has to be used to precisely estimate the location, pattern and width of cracks according to a given ground trough. Of course, numerical tools have to be previously calibrated according to the study of real case studies. For this reason, and to complete the back analysis of the present case study, a numerical tool is applied to assess the reliability of FE methods in predicting building damage induced by tunneling subsidence. A detailed comparison of the results produced by the different methods allows to achieve practical conclusions on the application of those methods appraised in this paper. All these analyses become especially significant since a comprehensive geometric survey and mechanical characterization of the constituent materials of the buildings were carried out, providing realistic parameters to the advanced models used in damage prediction.

\section{Case study}

\subsection{Introduction}

The Metro Line 9 in Barcelona is a reference tunneling project due to its total length of shield driven tunnels of more than $40 \mathrm{Km}$ and large excavation diameters $(9,4 \mathrm{~m}$ and $12,0 \mathrm{~m})$, encountering a wide variety of geological and hydrological conditions (Deulofeu et al., 2007). The case study corresponds to a neighborhood located at the north of the city, over an area of soft alluvium soils of the Besòs river delta. This zone represents one of the four main residential complexes built in 1929 in order to relocate workers coming from south Spain for the construction works developed for the World Exposition celebrated in the city. Nowadays, a reconstruction of the neighborhood is being done with the demolition of the oldest houses and the relocation of tenants in several new buildings, achieving the most substantial improvement for the neighborhood with the arrival of the Metro Line L9 in 2010.

The key factors in the present analyses are: (1) the poor bearing capacity of the soil, (2) the presence of groundwater, (3) the low depth of the tunnel $\left(z_{0}\right)(15 \mathrm{~m}$ from surface to tunnel axis, only $9 \mathrm{~m}$ of overburden) and (4) the initial state of the adjacent buildings (constructed at the end of 1920's). Therefore, a set of instrumentation was placed in the zone to continuously register ground and building movements (Figure 2). Data available for the research included the measurements from total stations of 30 retro-reflective prisms installed on building facades to control vertical and horizontal movements produced by the underpass of the TBM. After discarding the prisms out of the tunnel influence zone and the data noise, the measurements from 15 prisms were used to determine ground movements in the area (check Appendix B). These measurements were taken daily for a period from several weeks before the tunnel face underpass to four years after. This period was established to control the stabilization of ground movements due to long-term effects such as consolidation, which can increase settlements with time.

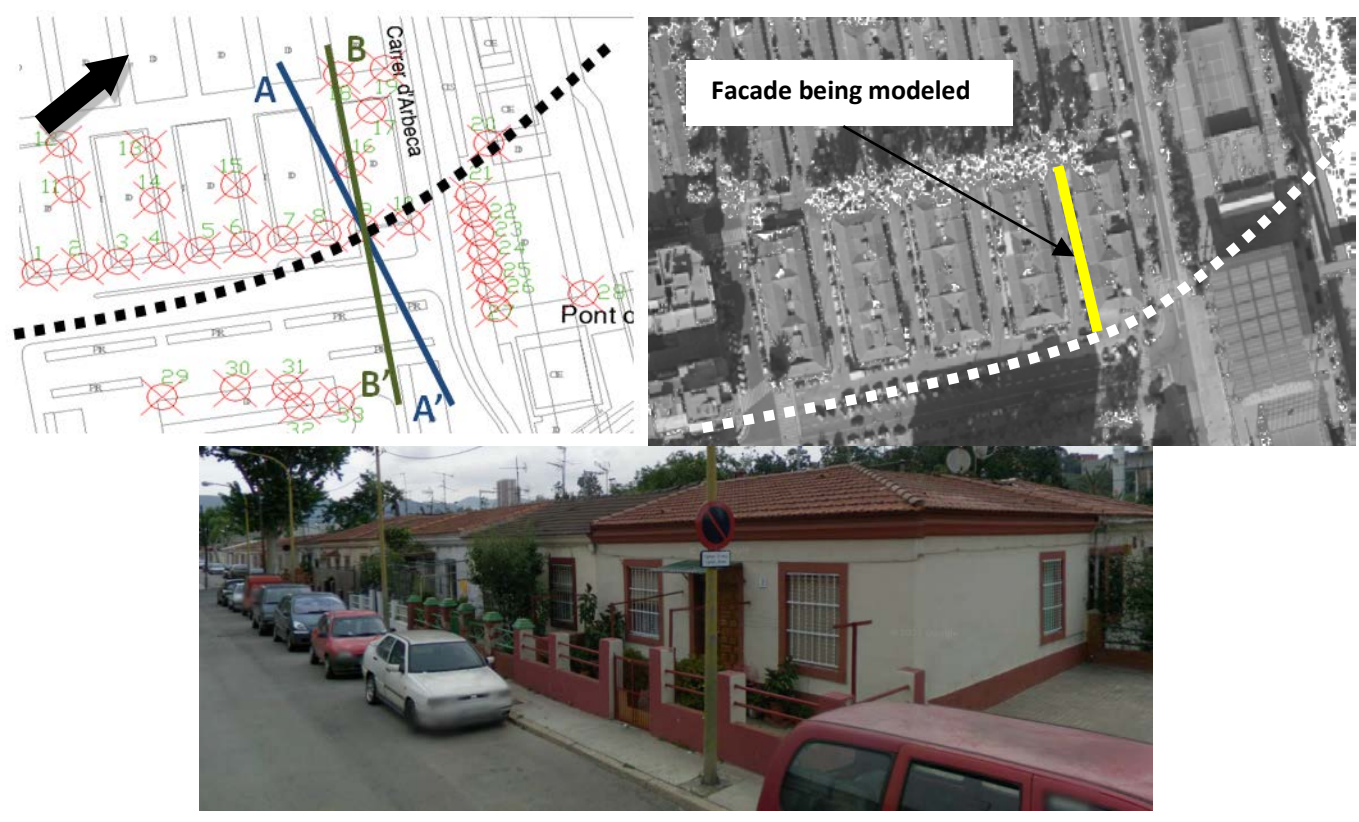


Figure 2 a) Monitoring points, tunnel track and studied sections in Bon Pastor, (BCN) - b) Facade being modeled c) Street view of the dwellings

\subsection{Geometrical, mechanical and chemical surveys of the buildings}

A comprehensive inspection was carried out, which included a characterization of the materials' structural properties and a geometrical survey. It was found that most of the dwellings inspected had a square plan of dimensions $8 \times 8 \mathrm{~m}$ and a terrace in the front part. Facade walls are mainly built with ceramic brick masonry, with unit dimensions of $29 \times 14 \times 4 \mathrm{~cm}$. However, in some dwellings, it was also possible to find solid concrete blocks of $30 \times 20 \times 20 \mathrm{~cm}$ or even a mixture of clay brick and concrete block masonries.

The facade wall under analysis (see location in Figure $2 \mathrm{~b}$ ) is composed of ceramic bricks and it is $20 \mathrm{~cm}$ thick. This length is the sum of $14 \mathrm{~cm}$ of a row of horizontal ceramic bricks, $2 \mathrm{~cm}$ of lime mortar and $4 \mathrm{~cm}$ of another row of bricks set up vertically (Figure 3). Partition walls are $4 \mathrm{~cm}$ thick (the bricks are laid on the stretchers). Sloping roofs sustained by timber beams are mainly used, although most of these beams have been replaced by pre-stressed concrete beams due to the rotting that many presented. These structures are supported by columns of brick masonry forming an 'L' shape in section to save material consumption. In addition, partition walls are attached to these brick masonry columns.
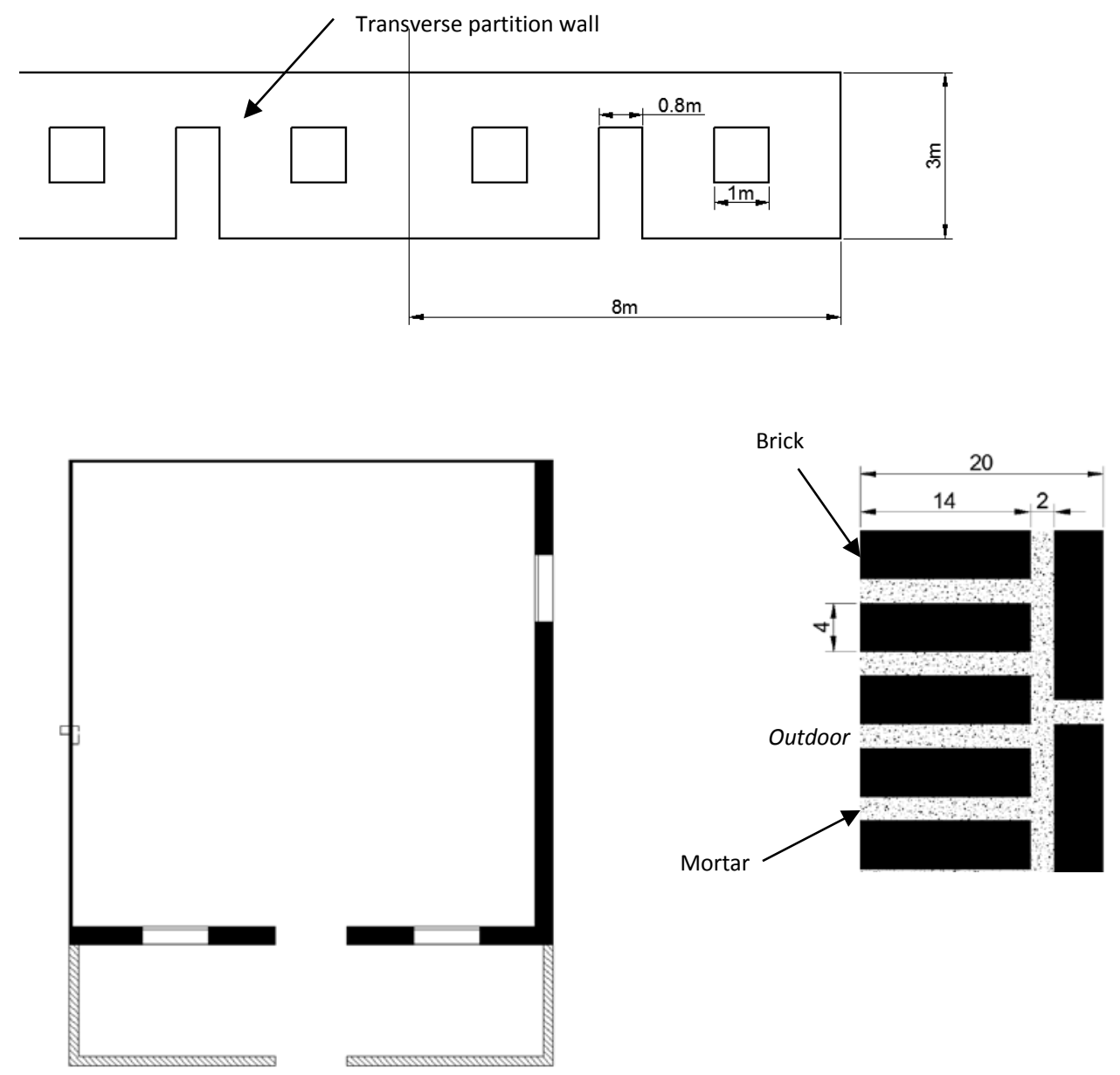

Figure 3 Elevation and plan of dwellings // Section (in $\mathrm{cm}$ ) of the facade

Penetration tests are applicable to estimate the in-place strength of mortar, according to a given relationship experimentally established between penetration resistance and mortar strength. Several of these tests were carried out to estimate an approximation of the in situ strength of mortar in the facade and in a central column supporting the roof (Table 1) according to the ASTM C-803 standards (2010). 
As it can be observed in Table 1, mortar used in columns presented a high average strength (28.7MPa) with low scatter $(C V=10.4 \%)$. On the other hand, the mortar used in walls had a lower strength of $1.7 \mathrm{MPa}$ with a higher scatter of results ( $\mathrm{CV}=75.9 \%)$. However, this is misleading because such high value of the coefficient of variation is derived from the low average value of this mortar. The notable difference of strength between the mortar used in walls and in columns suggested a different composition of them.

X-Ray diffraction (XRD) techniques are applicable to provide the structural analysis of polycrystalline samples of unknown materials. XRD analyses were performed in both mortars extracted from the facade wall and from columns. Phase identification was accomplished by comparing the peaks and relative intensities of the XRD patterns for each sample. Figure 4 shows an example of diffraction pattern from the mortar used in the columns, indicating a relative high presence of larnite $\left(\mathrm{Ca}_{2} \mathrm{SiO}_{4}\right)$ and porlandite $\left(\mathrm{Ca}(\mathrm{OH})_{2}\right)$ with quarz sand $\left(\mathrm{SiO}_{2}\right)$. In the pattern of the mortar used in the facade wall there was a total absence of porlandite. This fact, in addition to the much higher strength shown in the mortar of columns, lead to the conclusion that a cement type mortar was used, whereas a lime type was used in the facade wall. This difference in composition is actually noticeable to the naked eye due to the darker grey color of cement mortar (Figure $5(a-b))$.

The compressive strength of the ceramic bricks from the facade has been determined according to the procedures of EN 772-1 (2002), thus providing realistic parameters to the models as for Young and shear modulus and compressive strength in both axes. The results of three specimens are shown in Table 2. Afterwards, the measured strengths of mortar and bricks are employed to determine the characteristic strength of masonry according to the expressions from the Eurocode 6 (EN 1996-1-1:2005) for solid clay brick, which has been further converted to an average value (4.90 MPa) according to the transformation proposed by Melchers (1987). The vertical modulus of elasticity is determined by the expression of Kaushik et al. (2007), giving a result of rounding off till 2680MPa.

Assuming the same compressive strength of bricks in columns than in facade, these values increased up to $11.39 \mathrm{MPa}$ and $6250 \mathrm{MPa}$ in columns. It must be kept in mind that the latter assumption is conservative, since the chemical analysis have shown a higher quality of bricks used in columns but no entire bricks could be extracted from there to carry out a compressive strength test. The present characterization of materials has been employed in the predictions of damage on buildings due to the underpass of the TBM. On the other hand, it was not possible to carry out tests to determine the tensile strength and hence, these values had to be assumed from literature.

\begin{tabular}{|c|c|c|c|c|}
\hline \multirow[b]{2}{*}{$\begin{array}{c}\text { Reading } \\
\text { num. }\end{array}$} & \multicolumn{2}{|c|}{$\begin{array}{c}\text { Facade and } \\
\text { partition walls }\end{array}$} & \multicolumn{2}{|c|}{ Column } \\
\hline & $\begin{array}{l}\text { Microm. } \\
\text { reading }\end{array}$ & $\begin{array}{l}\text { Strength } \\
(\mathrm{MPa})\end{array}$ & $\begin{array}{l}\text { Microm. } \\
\text { reading }\end{array}$ & $\begin{array}{l}\text { Strength } \\
(\mathrm{MPa})\end{array}$ \\
\hline 1 & 0.554 & 0.2 & 0.816 & 24.4 \\
\hline 2 & 0.582 & 1.2 & 0.887 & 31.1 \\
\hline 3 & 0.571 & 0.3 & 0.867 & 29.3 \\
\hline 4 & 0.594 & 2.4 & 0.876 & 30.1 \\
\hline 5 & 0.601 & 2.8 & & \\
\hline 6 & 0.602 & 3 & & \\
\hline \multicolumn{2}{|c|}{ Mean (MPa) } & $1.7 \mathrm{MPa}$ & & $28.7 \mathrm{MPa}$ \\
\hline \multicolumn{2}{|c|}{ CV (\%) } & $75.9 \%$ & & $10.4 \%$ \\
\hline
\end{tabular}

Table 1 Penetrometer test results in facade

\begin{tabular}{|c|c|c|c|c|c|}
\hline Sample & $\begin{array}{c}\text { Mean length } \\
(\mathrm{mm})\end{array}$ & Mean width (mm) & $\begin{array}{c}\text { Mean thickness } \\
(\mathrm{mm})\end{array}$ & Load (kN) & $\begin{array}{c}\text { Compressive strength } \\
(\mathrm{MPa})\end{array}$ \\
\hline 1 & 289 & 139 & 41 & 445.34 & 11.06 \\
\hline 2 & 210 & 139 & 39 & 570.66 & 19.55 \\
\hline 3 & 152 & 140 & 43 & 506.15 & 23.69 \\
\hline Mean & & & & & $18.01 \mathrm{MPa}$ \\
\hline CV & & & & & $35.6 \%$ \\
\hline
\end{tabular}

Table 2 Compression strength tests for ceramic brick samples 


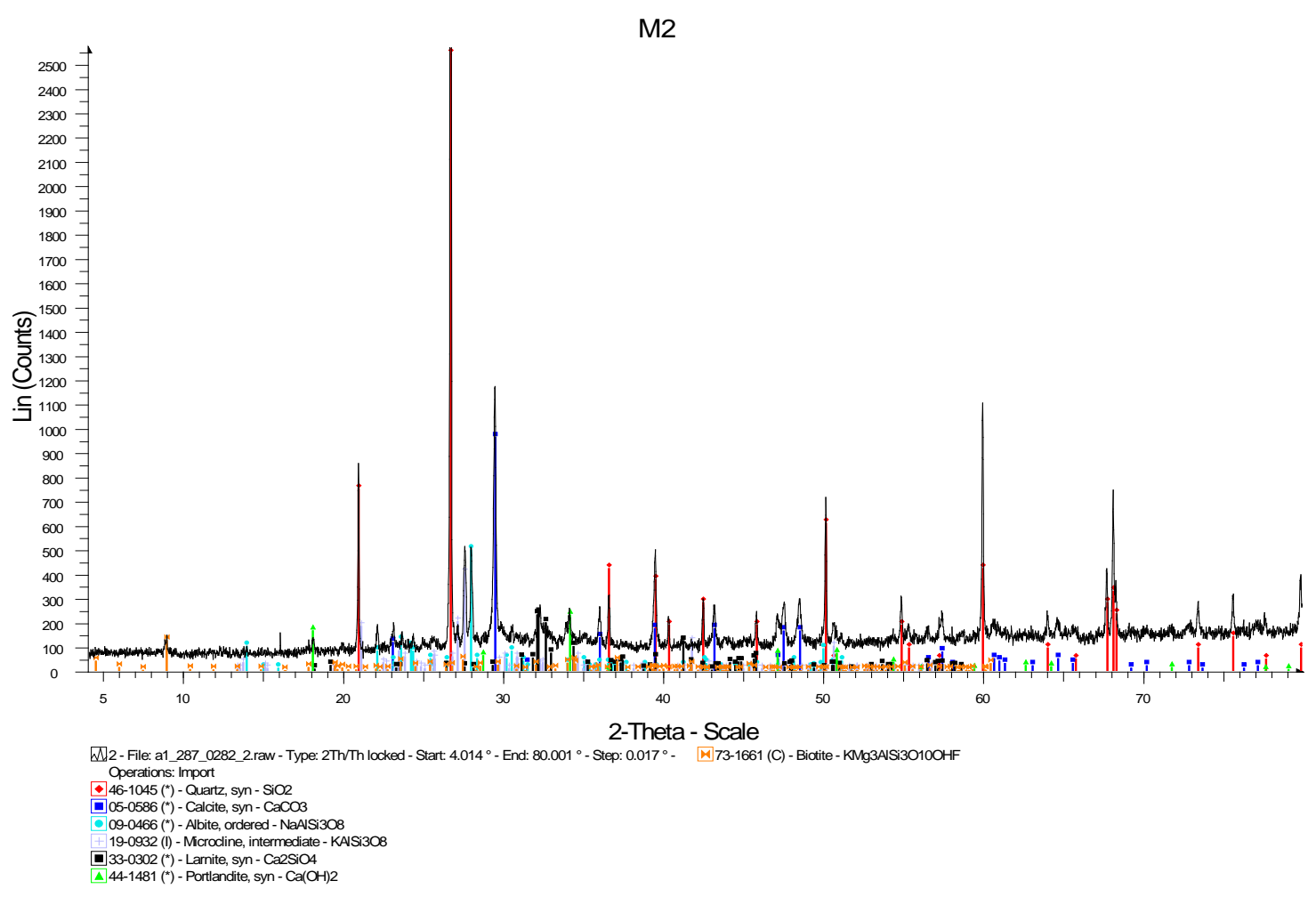

Figure 4 Chemical analysis of a lime mortar sample using X-Ray diffraction (note the high presence of calcite)
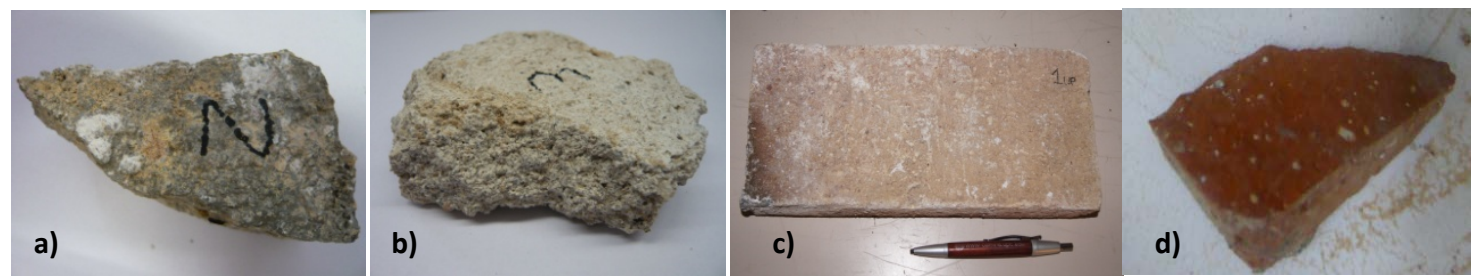

Figure 5 (a) Fragment of cement mortar used in columns, (b) fragment of lime mortar used in walls, (c) clay brick used in walls, (d) fragment of clay brick used in columns

\section{Prediction of ground movements}

Ground movements in section A-A' (Figure 2) are studied to test the suitability of the methods used in the prediction of settlements and horizontal movements. The approaches from Peck (1969), Attewell et al. (1986) and Rankin (1988) are used, assuming a Gaussian distribution curve for the transverse profile of the trough. The soil in the zone of study is characterized by the interbedding of sediment layers with a high variety of grain particle distributions (grained sands, gravels and blocks in a sandy matrix, clay and silts and coarse sands and gravels) (Deulofeu et al., 2007). According to this type of soil, the trough width parameter $K$ is chosen equal to 0.5 (O'Reilly, 1982). For a tunnel of $12 \mathrm{~m}$ diameter $(D)$ and $15 \mathrm{~m}$ depth $\left(z_{0}\right)$, the location of the points of inflection (i) will be at a distance equal to half-depth $(7.5 \mathrm{~m})$ from tunnel centerline (O'Reilly, 1982). The maximum settlement $\left(s_{\max }\right)$ will occur above the tunnel axis and its magnitude depends on the ground loss $\left(V_{L}\right)$, which is inherent to the construction method employed. Typical values for tunnels drilled by TBM-EPB are in the range of $0.3 \%-0.6 \%$ with maximum values of $1.0 \%$ (Gatti \& Cassani, 2007). In granular soils, higher values are expected, mainly when bored under the ground water table. Therefore, an average volume loss of $0.75 \%$ is considered, giving a maximum estimated settlement value of $45 \mathrm{~mm}$ (a more detailed evaluation is shown in Appendix B).

The predicted settlement profile corresponds to the dashed line in Figure 6, whereas the small triangles correspond to the real measured values of settlement, with a maximum value of $41 \mathrm{~mm}$. Therefore, the prediction of maximum settlement was notably well adjusted to reality, with only a difference of about 
$10 \%$. The continuous line corresponds to the Gaussian curve which best fits the real settlements (Kim et al. 2001), showing the acceptable adjustment of the settlement profile to a Gaussian shape.

It must be kept in mind that these calculations estimate the maximum immediate settlement when tunnel face is under the buildings, and do not take into account long-term effects such as ground consolidation, which could increase subsidence with time. In this particular case, the maximum settlement value rose up to $54 \mathrm{~mm}$, four years after the TBM underpass.

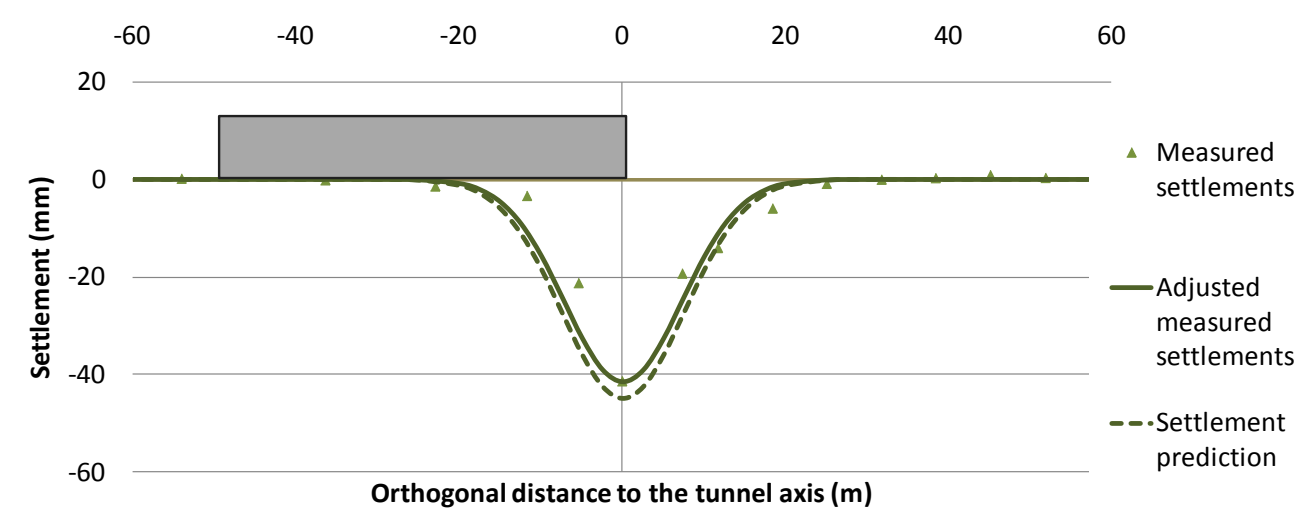

Figure 6 Immediate settlement profile (predicted, measured and adjusted)

Horizontal displacements $(u)$ and strains $\left(\varepsilon_{h}\right)$ (continuous lines in Figure 7 and Figure 8 ) were predicted according to the expression given by O'Reilly (1982), assuming that the overall movement of ground is directed towards tunnel axis. It can be seen that the two plots are notably different from real measurements (small rhombus). It must be taken into account that only measurements from prisms located at mid-height of dwellings were available. Therefore, the comparison between predictions and real measurements must be taken with care since the foundations will partly prohibit the complete transmission of the horizontal ground strains. In the case of vertical displacements of ground, available measures taken by other instruments placed at ground level in the proximity of the buildings showed similar values to the ones registered by the prisms at mid-height. Moreover, the adjustment of these measurements to a Gaussian profile (as in green-field conditions) allow to assume a notable flexible behavior of the building in the vertical direction.

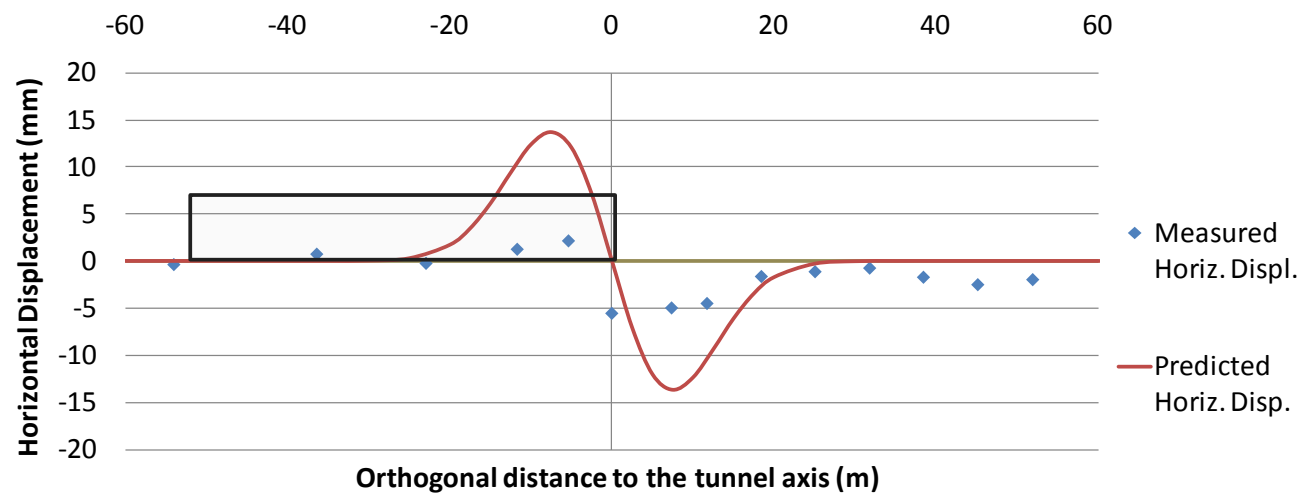

Figure 7 Horizontal displacements in monitoring section 


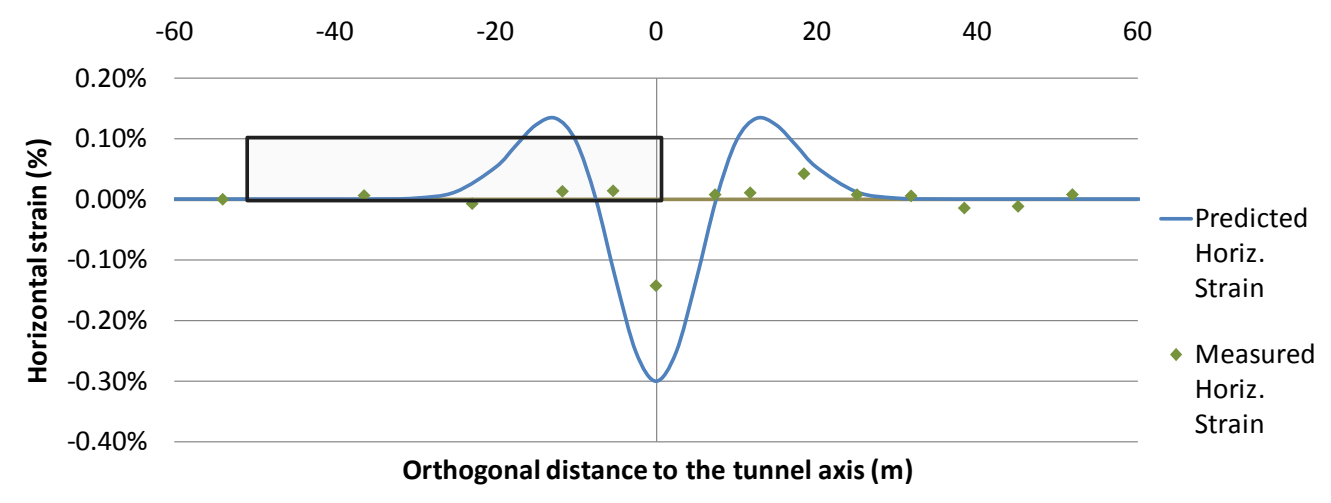

Figure 8 Horizontal strain according to horizontal displacements measured in ground

\section{Prediction of damage on buildings using the classical methodology}

\subsection{Determination of deflection ratios}

A first estimation of the damage on the group of dwellings due to the TBM underpass is carried out using the 'equivalent beam' method. This approach assumes that the parts of the buildings under sagging (upward concavity of the settlement profile) and hogging (downward concavity) can be treated as independent beams. Therefore different, deflection ratios $(\Delta / L)$ for each part must be considered (Figure 9). These ratios are determined in four steps: (1) assessment of the settlement profile, (2) plot of the straight lines joining the inflection point and the maximum and minimum settlements affecting the total length of the building, (3) determination of the maximum differences between these lines and the settlement profile (relative deflection, $\Delta$ ) and (4) division of these values by the respective lengths of sagging and hogging.

Considering the predicted settlement profile of section 3, and projecting it to the section of the facade, the length of the building affected by sagging deflection is $L_{s a g}=8.2 \mathrm{~m}$, whereas in hogging is $L_{\text {hog }}=38.3 \mathrm{~m}$. The values of relative deflection $(\Delta)$ are $3.57 \mathrm{~mm}$ in sagging and $16.66 \mathrm{~mm}$ in hogging. Therefore, the deflection ratios in both modes of deflection match up to $(\Delta / L)=0.04 \%$.

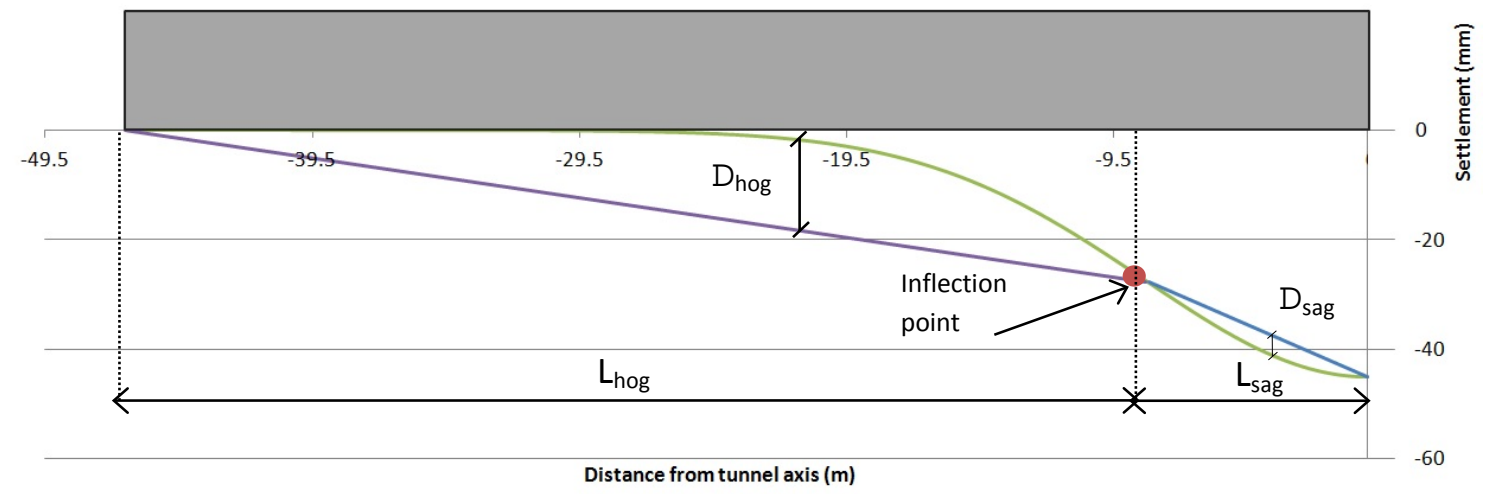

Figure 9 Determination of the deflection ratios in sagging and hogging

\subsection{Burland \& Wroth (1974) and Boscardin \& Cording (1989) approach}

Maximum tensile strains are calculated at each part of the beam for a depth $(H)$ equal to $3 m$, inertia per unit length equal (I) to $2.25 \mathrm{~m}^{4} / \mathrm{m}$ and a relationship $E / G=2.5$ (Devriendt, 2003), typical for structures assumed to be linear elastic, isotropic and homogenous base upon Poisson ratios of 0.2 to 0.3 being used (check Appendix $C$ to follow the values used within the analysis). Two extreme modes of deformation (bending only $\varepsilon_{b \max }$ and shearing only $\varepsilon_{d \max }$ ) are assumed to ascertain which type is limiting. The 'equivalent beam' method requires to take an independent decision about the position of the neutral axis $(t)$ in each part of the building. In hogging, due to the inability of the masonry in the upper part of the wall to withstand significant tensile stresses, the neutral axis is likely to be nearer to the 
foundations. In sagging mode, however, the lower part of the masonry wall tends to be capable of withstanding tensile stress and therefore the neutral axis can be considered as being at mid-depth of the wall (Mair et al. 1996).

Tensile stresses in the wall mainly occur due to the deflection induced to the beam. Moreover, in certain parts of the building, ground movements can induce additional stresses that can produce a higher level of damages. The influence of this horizontal ground strain $\left(\varepsilon_{h}\right)$ can be introduced by superposition using the approach of Boscardin \& Cording (1989), giving the resultant extreme fiber strain in bending $\left(\varepsilon_{b r}\right)$ and in shearing $\left(\varepsilon_{d r}\right)$. As can be seen in Figure 8 , the predicted ground strain is not constant along the building length and hence, the designer has to deal with the election of a particular value, which is in fact somewhat unreal. Considering the maximum value of ground strain could lead in an overestimated damage category, since the coordinate corresponding to the maximum ground strain could not match the coordinate where the tensile strains in the equivalent beam are maximum (however, these values corresponding to different points of the beam are combined in the same Mohr's circle). To avoid overestimation, a mean value of ground strain will be considered in both modes of deflection:

a. Hogging part: the high length of the building undergoing hogging results in negligible ground strain values in nearly a half of the total hogging length. Thus, if an average value is taken over the whole length of hogging, it might be underestimated. Then, the mean value of ground strain in hogging is taken only in the most critical half length (approximately from coordinates $y=-24 m$ and $y=-8.2 m$ in Figure 9)

b. Sagging part: The study of Boscardin and Cording (1989) only examined cases where the lateral strains were positive (tensile strains). The nature of strain in sagging zones is compressive, thus giving a favorable contribution for damage resistance a priori. Therefore, the approach of Boscardin and Cording cannot be applied in sagging. A conservative approximation is taken considering null ground tensile strain in this part of the buildings and hence the favorable contribution of compressive strains to damage reduction is not considered.

Strain results given by the 'equivalent beam' are shown in Table 3 (the detailed evaluation is provided in Appendix C). The major damage is given by bending in the part subjected to hogging deflection, with an assessed damage equal to Category 2 ('Slight'). According to the classification given by Burland et al. (1977) and Boscardin and Cording (1989), this category implies the onset of cracking that could be easily filled. Cracks could be visible externally and some repointing might be required to ensure weathertightness. The typical crack widths are up to approximately $5 \mathrm{~mm}$. As it is further shown in Section 6, this description of damage agrees with the actual crack width as observed during the tunneling.

\begin{tabular}{l|c|c|c|c|c|c|c}
\hline \multicolumn{2}{l}{ Burland \&Wroth (1974) and Boscardin \& Cording (1989) approaches } \\
\hline & $\boldsymbol{D}_{\max } / \mathbf{L}$ & $\boldsymbol{\varepsilon}_{\text {h mean }}$ & $\boldsymbol{\varepsilon}_{\text {bmax }}$ & $\boldsymbol{\varepsilon}_{\text {dmax }}$ & $\boldsymbol{\varepsilon}_{b r}$ & $\boldsymbol{\varepsilon}_{d r}$ & $\begin{array}{c}\text { Assessed category of } \\
\text { damage }\end{array}$ \\
\hline Sagging & $(+) 0.04$ & $0.000 \%(*)$ & $(+) 0.058 \%$ & $(+) 0.013 \%$ & $(+) 0.058 \%$ & $(+) 0.013 \%$ & VERY SLIGHT (CAT. 1) \\
\hline Hogging & $(-) 0.04$ & $(+) 0.069 \%$ & $(+) 0.037 \%$ & $(+) 0.001 \%$ & $(+) 0.106 \%$ & $(+) 0.069$ & SLIGHT (CAT. 2) \\
\hline
\end{tabular}

Table 3 Equivalent beam strain results

$\left({ }^{*}\right)$ Note that ground strain is considered negligible since the approach of Boscardin and Cording (1989) only applies to cases of tensile lateral strains.

\subsection{Modification factors from Potts \& Addenbrooke (1997)}

As it was mentioned in the introduction, the application of the 'equivalent beam' method from Burland \& Wroth assumes that the building conforms perfectly to the 'greenfield site' subsidence trough. However, in practice, the inherent stiffness of the building will be such that its foundations may interact with the ground and thus reduce the deflection ratio and horizontal strains. Therefore, the modification factors from Potts \& Addenbrooke (1997) are applied here, updating the deflection ratios and the horizontal ground strains. These factors $(M)$ depend on the eccentricity $(e / B)$ of the tunnel with respect 
to the building centerline and to the relative axial $\left(\alpha^{*}\right)$ and bending $\left(\rho^{*}\right)$ stiffness of the structure. For a relative stiffness parameters $\alpha^{*}=11.9$ and $\rho^{*}=0.0007(1 / \mathrm{m})$, the modification factors of the deflection ratios sagging and hogging respectively $M^{\text {DRsag }} \approx 0.5$ and $M^{\text {DRhog }} \approx 1.2$. For the horizontal ground strain in compression and tension regions, factors are $M^{\varepsilon_{h c}} \approx 0.01$ and $M^{\varepsilon_{h t}} \approx 0.01$, giving the strain results shown in Table 4 (see Appendix $C$ for further information).

\begin{tabular}{l|c|c|c|c|c|c|c}
\hline \multicolumn{7}{l}{ Application of Potts \& Addenbrooke (1997) factors } \\
\hline & $\boldsymbol{D}_{\text {max }} / \boldsymbol{L}$ & $\boldsymbol{\varepsilon}_{\text {h media }}$ & $\boldsymbol{\varepsilon}_{\text {bmax }}$ & $\boldsymbol{\varepsilon}_{\text {dmax }}$ & $\boldsymbol{\varepsilon}_{b r}$ & $\boldsymbol{\varepsilon}_{d r}$ & $\begin{array}{c}\text { Assessed category of } \\
\text { damage }\end{array}$ \\
\hline Sagging & $(+) 0.02$ & $0.000 \%(*)$ & $(+) 0.029 \%$ & $(+) 0.007 \%$ & $(+) 0.029 \%$ & $(+) 0.006 \%$ & NEGLEGIBLE (CAT. 0) \\
\hline Hogging & $(-) 0.05$ & $(+) 0.0007 \%$ & $(+) 0.044 \%$ & $(+) 0.001 \%$ & $(+) 0.045 \%$ & $(+) 0.001 \%$ & NEGLEGIBLE (CAT. 0) \\
\hline
\end{tabular}

Table 4 Equivalent beam strain results (modification factors applied)

Once again, bending deflection is dominating instead of shearing. However, the resulting category of damage is 'Negligible' in both deflection modes. This reduction of the predicted damage is mainly given by the dramatic reduction of the horizontal strain coming from ground. Potts \& Addenbrooke showed in their numerical analysis that the tensile strains could be reduced in a $90 \%$ respect to those calculated assuming greenfield conditions. Nevertheless, as it will be seen in Section 6, the assessed category of damage using this approach is clearly underestimated compared to the real damage occurred. According to Potts \& Addenbrooke design charts, the modification factor for horizontal strain in tension and compression is low (<0.01) for realistic axial stiffness of buildings (i.e. $\alpha^{*}>10$ ) (Dimmock, 2008), also for the case study. Therefore, not all the walls would be represented in these design charts and hence the results obtained by this approach should be considered with care.

\section{Numerical simulation using a Finite Element Method: 'Rankine Hill' macro-model}

\subsection{Introduction}

The structural behavior of the set of dwellings subjected to subsidence is simulated by using a FE model in DIANA ${ }^{\circledR}$ software (TNO, 2005). The modeling consists in a 2D non-linear plane stress analysis using the macro-model 'Rankine-Hill' proposed by Lourenço (1996), which includes cracking effects in tension and crushing in compression. Plastic strain contours make it possible to obtain the crack patterns of the structure, which will be already compared with the damage surveys done during the construction of $L 9$.

\subsection{Description of the model}

The geometry of the model is represented by Figure 3. The dimensions of each dwelling are $3 m$ height and $8 \mathrm{~m}$ wide. All of them have two windows of dimensions $1 \times 1 \mathrm{~m}$ and a door of $2 \mathrm{~m}$ height and $0.80 \mathrm{~m}$ wide, repeating this pattern of openings along the six dwellings.

In the present numerical analysis, the entire facade is considered as a ceramic brick masonry wall $20 \mathrm{~cm}$ thick. Although a 2D plane stress model is assumed, certain assumptions will be done at the level of the transverse walls. The effect of the out-of-plane elements such as transverse partition walls of $4 \mathrm{~cm}$ brick masonry has been introduced using thicker elements in these zones, and hence the stiffness at these zones is also higher. An extra thickness of $30 \mathrm{~cm}$ is given (having $50 \mathrm{~cm}$ width in total in these elements, $20 \mathrm{~cm}$ corresponding to the facade itself width $+30 \mathrm{~cm}$ of length out of plane).

When the 'equivalent beam' method was previously used, ground movements were assumed to follow a Gaussian profile according to relative simply hypotheses. Therefore, when doing the prediction of damage, the evaluation was about the global quality of both ground movements and the structural damage assessment. However, when using the numerical approach, it would be desirable to pay attention the most as possible only to the quality of the numerical model in order to assess the reliability of FE methods in building damage prediction. Thus, it is intended to work with real ground movements to avoid distortion in the results, instead of using predictions given by classical methods. Since the available real measurements of settlements are limited, an interpolation process is carried out based on a Gaussian trough according to literature (Peck, 1969; Attewell et al., 1986; and Rankin, 1988). 
The analysis is performed considering plane stress. Thus, only in-plane actions are taken into account (self-weight, roof load, settlements and horizontal movements from ground). Self-weight was determined according to the typical value of masonry density $\left(1800 \mathrm{Kg} / \mathrm{m}^{3}\right)$. According to the Spanish regulations, the typical self-weight value for a tile roof with false ceiling (constructed with gypsum mortar and canes) can be estimated in $2.5 \mathrm{KN} / \mathrm{m}^{2}$. This load is acting in a roof surface of $8 \times 8 \mathrm{~m}$ and thus giving a uniform load on the facade of $10 \mathrm{KN} / \mathrm{m}$.

The settlement profile will be given by the Gaussian curve which best fits the real settlement measures (see continuous line in Figure 6, with curve parameters $i=7.18 \mathrm{~m}$ and $s_{\max }=41 \mathrm{~mm}$ ) projected along the building length (26o rotation, Figure 2 ). As regards to real horizontal movements $(u)$, they do not follow a clear trend or shape. For this reason, linear regression is applied between real measures to obtain the whole profile along the building.

The mesh consist of 11790 4-nodes quadrilateral isoparametric plane-stress elements (Q8MEM). The element width was set up at $0.1 \mathrm{~m}$, thus giving a perfectly rectangular mesh which made possible to obtain results with an acceptable precision for this case study.

A model based in the mathematical approach of Winkler (Muzás, F., 2002) is here used to represent the behavior of the soil. Interaction between soil and foundations in the vertical direction is simulated by a set of non-linear springs, whose compression stiffness $\left(K_{s}\right)$ has been estimated according to the subgrade reaction modulus of ground, taken as $0.09 \mathrm{~N} / \mathrm{mm}^{3}$ for the present type of soil with grained sand and clay and silts, typical from a river delta (Calavera, 2000). A continuous foundation of $30 \mathrm{~cm}$ has been assumed, since no real dimensions were available. This set of springs remain inactive $\left(K_{s}=0\right)$ for tensile strains in order to simulate the gapping phenomenon. The modeling in the horizontal direction is performed in a similar way, now setting out linear springs also with the same constant $K_{s}$. Horizontal springs remain inactive in zones where soil-foundation contact is lost.

The material response has been adopted according to the values obtained experimentally (Table 5). The ratio between the vertical and the horizontal modulus of elasticity of masonry $\left(E_{y} / E_{x}\right)$ is taken as 0.8 , according to Samarashinge et al. (1982). For the ratio between vertical and horizontal maximum compression strength $\left(f_{c y} / f_{c x}\right)$, a value of 1.5 was proposed by the same authors and Sandoval (2011). Other values needed for the analysis have been assumed according to general properties of masonry and previous studies from Barbosa (2010) (Table 5, where $G$ is the shear modulus, $v$ is the Poisson's ratio, $G_{f x}$ and $G_{f y}$ are the fracture energies in the horizontal and vertical direction respectively, and $f_{t x}$ and $f_{t y}$ are the horizontal and vertical tensile strength of masonry).

\begin{tabular}{c|c|c|c|c|c}
\hline $\boldsymbol{E}_{\boldsymbol{x}}{ }^{(*)}$ & $\boldsymbol{E}_{y}{ }^{(*)}$ & $\boldsymbol{G}^{\left({ }^{*}\right)}$ & $\mathbf{n}^{\left({ }^{* *}\right)}$ & Density $^{(* *)}$ & $\boldsymbol{K}_{s}{ }^{(* *)}$ \\
\hline $3350 \mathrm{MPa}$ & $2680 \mathrm{MPa}$ & $1070 \mathrm{MPa}$ & 0.20 & $1800 \mathrm{Kg} / \mathrm{m}^{3}$ & $2700 \mathrm{~N} / \mathrm{mm}$ \\
\hline $\boldsymbol{f}_{t x}{ }^{\left({ }^{* *}\right)}$ & $\boldsymbol{f}_{t y}{ }^{\left({ }^{* *}\right)}$ & $\boldsymbol{G}_{f x}{ }^{(* *)}$ & $\boldsymbol{G}_{f y}{ }^{(* *)}$ & $\boldsymbol{f}_{c x}{ }^{(*)}$ & $\boldsymbol{f}_{c y}{ }^{\left({ }^{*}\right)}$ \\
\hline $0.10 \mathrm{MPa}$ & $0.05 \mathrm{MPa}$ & $2.0 \mathrm{~N} \cdot \mathrm{mm} / \mathrm{mm}^{2}$ & $2.0 \mathrm{~N} \cdot \mathrm{mm} / \mathrm{mm}^{2}$ & $3.25 \mathrm{MPa}$ & $4.90 \mathrm{MPa}$ \\
\hline
\end{tabular}

Table 5 Model parameters - ${ }^{(*)}$ determined according to experimental values $/ /{ }^{(* *)}$ assumed values

\subsection{Results}

The deformed shape of the structure when ground movements are applied can be seen in Figure 10, giving the contour of plastic strains $\left(\varepsilon_{p 1}\right)$ of Figure 11 . As it can be seen, the most unfavorable plastic strains are concentrated in the corners of doors and windows, since they represent stress concentration points. The maximum value of plastic strain $(2.19 \%)$ is reached in the corner of the left window of the second dwelling, which is subjected to hogging. The maximum value in sagging is equal to $1.39 \%$. According to the plastic strains values, it is possible to determinate crack widths in the wall. Considering an element side size of $0.1 \mathrm{~m}$, the expected crack opening computed by the FE model is $2.19 \mathrm{~mm}$ in hogging and $1.39 \mathrm{~mm}$ in sagging.

However, the high difference between maximum and minimum plastic strains in Figure 11, may hide lower strains that could develop smaller cracks. Therefore, in Figure 12, plastic strains in a range from $0.9 \cdot 10^{-4}$ to $0.9 \cdot 10^{-3}$ are shown. As it can be seen, several diagonal strains appear in the first dwelling that could not be appraised in Figure 11. 


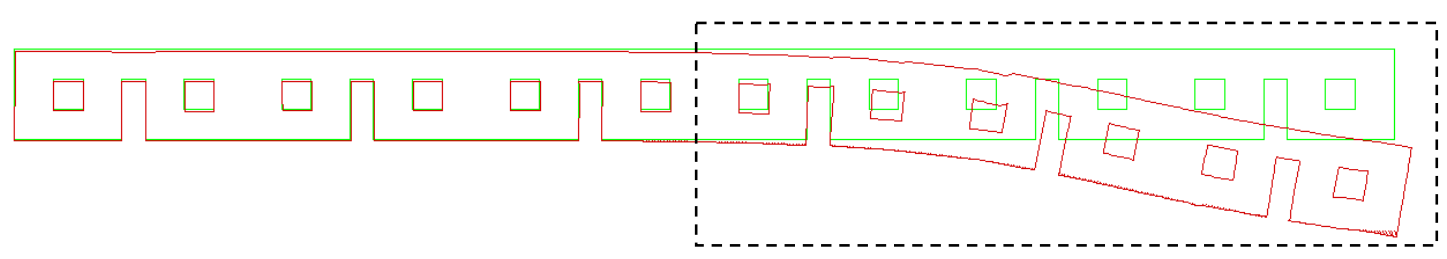

Figure 10 Deformed shape when ground movements are applied (Amplification factor=74.5)

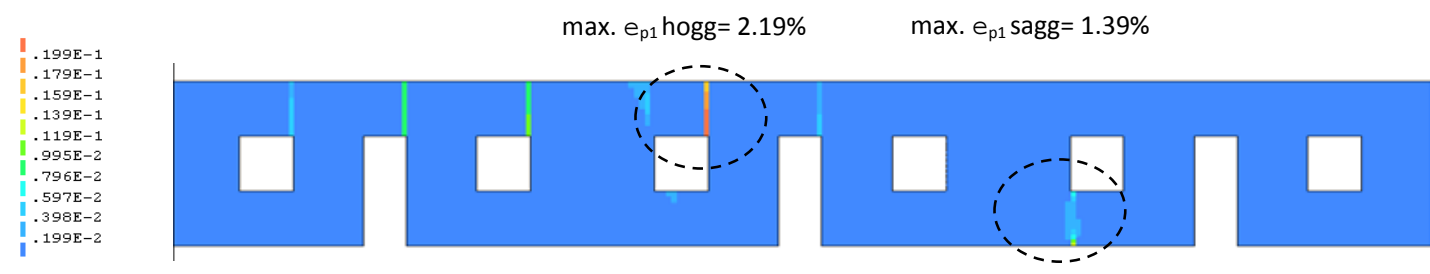

Figure 11 Maximum plastic strains/crack patterns (three last dwellings from right)

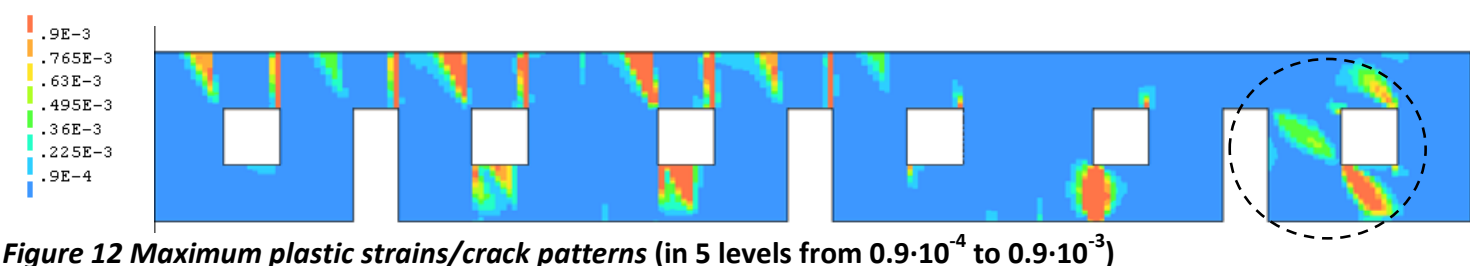

Figure 12 Maximum plastic strains/crack patterns (in 5 levels from $0.9 \cdot 10^{-4}$ to $0.9 \cdot 10^{-3}$ )

The finite element analysis showed a critical dependence on the horizontal movements $(u)$ from ground that tunneling can induce. In this case study, horizontal movements reached a maximum value of $2.4 \mathrm{~mm}$, becoming critical due to the produced distortion effects that substantially modify the distribution of the strain field. Therefore, the determination of the modulus of elasticity in the horizontal direction takes a remarkable importance. Higher is the modulus, higher stresses will be generated for the same field of strains. As a consequence, the accommodation of the building to the imposed profile of the ground implies a stress redistribution that will lead in an increment of plastic strains in zones where non-elastic effects had started, thus increasing the crack widths.

\section{Comparison between real damage and predictions}

\subsection{Description of real damage occurred}

Damage surveys ocurred during the construction of the tunnel consisted of several diagonal and vertical cracks, starting from corners of windows and doors till the lintel of the facade (Figure 13). Several shorter cracks appeared in the ledges of the facade windows. Horizontal cracking appeared in the base of the lateral wall of the group of dwellings. In particular, this wall played an important role, since it avoided a higher descent of the facade corner. Real crack widths were comprised between 1 and $3 \mathrm{~mm}$. According to the chart of Burland et al. (1977), the overall damage in the building can be classified as 'Slight' (Category 2).
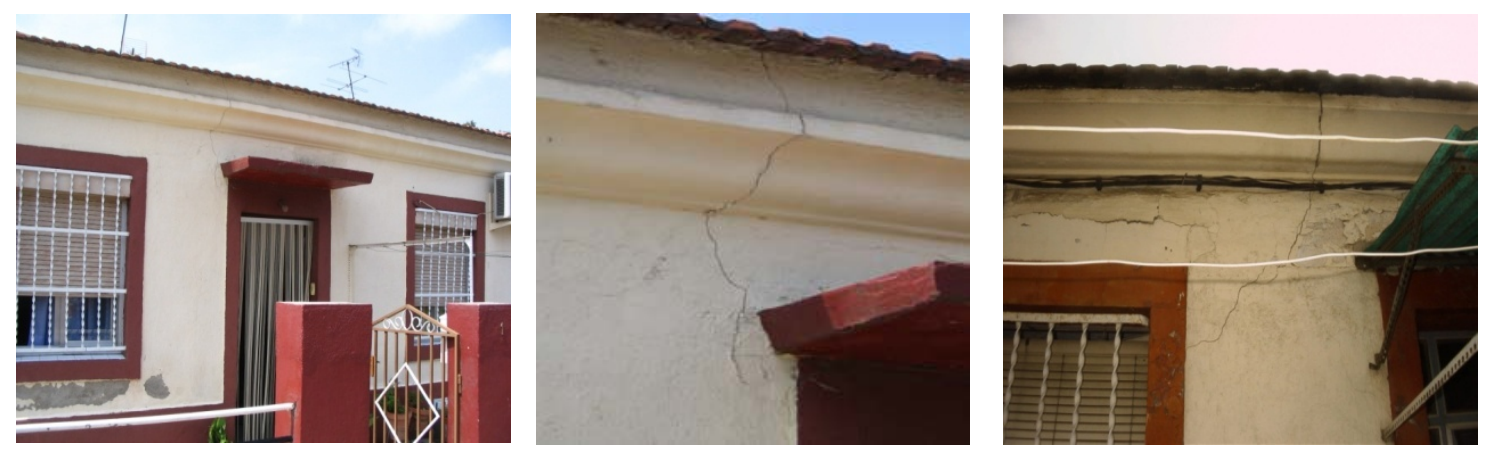


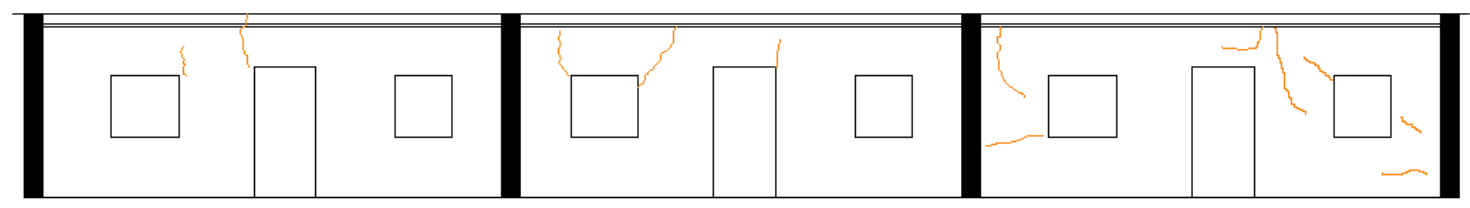

Figure 13 Damage occurred in buildings due to tunneling

\subsection{Comparison of real damage with non-linear numerical simulation and 'equivalent beam' results}

The crack patterns described by the Finite Element analysis (Figure 11 and Figure 12) are in notable agreement with most of the cracks registered in the surveys. As regards to the predicted crack widths, the numerical model values are $2.19 \mathrm{~mm}$ in hogging and $1.39 \mathrm{~mm}$ in sagging. Both measures are within the range of real craking occurred. According to the classification of visible damage to walls from Burland et al. (1977), the predicted categories of damage by numerical simulation would be 'Slight' (Category 2) for both parts. This fact agrees with reality and it can be globally said that the numerical tool shows a high degree of reliability in damage prediction due to tunneling.

The predicted categories of damage using the 'equivalent beam' approach from Burland \& Wroth (Section 4) were 'Slight' (Category 2) in hogging and 'Very slight' (Category 1) in sagging (Table 6). Therefore, the global prediction of damage in the building agrees with reality but, however, there is a difference in the prediction of damage in the part under sagging. This fact shows the inconvenience of the approaches when considering compressive strains coming from ground. On the other hand, the application of the modification factors from Potts \& Addenbrooke (1997) has predicted a negligible onset of damage in the structure. The surveys show that this assessment is clearly underestimated.

\begin{tabular}{c|c|l|l|l|l|l}
\hline & \multicolumn{2}{|c|}{ Reality } & \multicolumn{2}{c|}{ Numerical Non - Linear Analysis } & \multicolumn{2}{c}{ Equivalent beam } \\
\hline Sagging & $1-3 \mathrm{~mm}^{*}$ & Category 2 'Slight' & $1.39 \mathrm{~mm}^{*}$ & Category 2 'Slight' & $0.058 \% * *$ & Category 1 'Very Slight' \\
\hline Hogging & $1-3 \mathrm{~mm}^{*}$ & Category 2 'Slight' & $2.39 \mathrm{~mm}^{*}$ & Category 2 'Slight' & $0.106 \% * *$ & Category 2 'Slight' \\
\hline
\end{tabular}

Table 6 Comparison of real damage with non-linear numerical simulation and 'equivalent beam' results ( ${ }^{*}$ crack width, ${ }^{* *}$ maximum tensile strain)

\subsection{Comparison of linear elastic numerical simulation and the 'equivalent beam'}

By definition, the 'equivalent beam' method assumes linear elasticity. Then, classification of damage is based on the calculation of a maximum tensile strain in the elastic beam. This value is later compared with the limiting values of category of damage on buildings. For this reason, it is of interest to compare the predictions given by a linear analysis of the structure using numerical simulation and the results from the application of the equivalent beam to ascertain the equivalence of using both methods.

The distribution of principal strains $\left(\varepsilon_{X}\right)$ of the structure subjected to the predicted ground movements (recall Figure 6 and Figure 7) assuming linear elastic behavior of masonry is presented in Figure 14. In this case, the springs are not used, since ground movement is directly imposed in the foundations. The self-weight and the vertical loads coming from roof are disregarded. In the hogging part, the strain coming from ground is assumed to be constant and equal to $0.069 \%$ (as it was also assumed in the 'equivalent beam' calculations, section 4.2). In sagging, ground strain is assumed to be zero and hence, the horizontal displacements are constant in this part.

The maximum principal strain obtained value is equal to $0.270 \%$, located in the zone under hogging. If one takes into account this value, the predicted category of damage would be 'Moderate', with a critical affection on the serviceability of building. The reason of such high value lays in its location (in a window corner). As infinitely elasticity is assumed, these points act as a concentrator of stresses. Therefore, principal strains close to openings can be overestimated and should be considered with circumspection.

If these local values are disregarded and strain measures are taken in the extreme fibers of the facade (out of the openings influence), the resulting maximum values of principal linear elastic strains are then 
equal to $0.120 \%$ in the hogging zone and $0.062 \%$ in sagging (Figure 14). The resulting damage categories are 'Slight' (Category 2) for hogging and 'Very slight' (Category 1) for sagging.

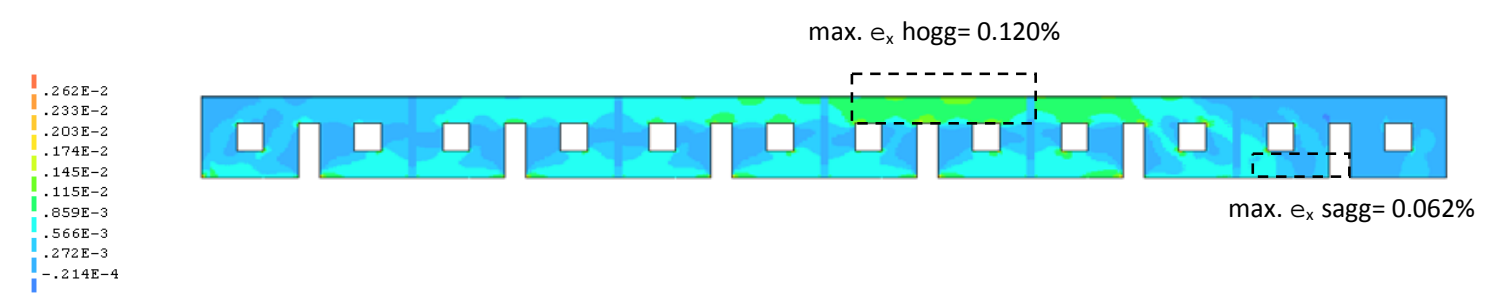

\section{Figure 14 Distribution of principal strains}

There is a clear similarity of maximum tensile strain values between the numerical prediction of the linear analysis and the assessment done with the 'equivalent beam' method (without the application of modification factors) (view Table 7). The predicted damage in hogging is 'Slight' (Category 2), which matches with the prediction of the non-linear numerical analysis and the reality. The predicted damage in sagging is classified as 'Very slight' (Category 1) for both methodologies. As it was mentioned in 6.1 and 6.2, the real damage occurred in this part of the building was classified as 'Slight' (Category 2). Therefore, the prediction is quite underestimated by both methods but however the global prediction of damage in the buildings is correctly done.

\begin{tabular}{r|l|l|l|l}
\hline & \multicolumn{2}{|c|}{ Numerical Elastic Linear Analysis } & \multicolumn{2}{c}{ Equivalent beam } \\
\hline Sagging & $0.062 \%$ & Category 1 'Very Slight' & $0.058 \%$ & Category 1 'Very Slight' \\
\hline Hogging & $0.120 \%$ & Category 2 'Slight' & $0.106 \%$ & Category 2 'Slight' \\
\hline
\end{tabular}

Table 7 Comparison of linear elastic numerical simulation and the 'equivalent beam' results

\section{Conclusions}

According to the monitoring data, it has been stated that the shape of the settlement trough can be well described as a normal Gaussian probability densitiy function for the transverse profile. Prediction of maximum settlement has given a difference of only $10 \%$ of the real measured value. Contrarly to the usual greenfield approximation, the prediction of the horizontal displacements requires the consideration of the interaction between the building and the soil. In practice, the presence of buildings and pavements tends to reduce the amount of vertical and horizontal movements of ground.

Damage prediction performed with the 'equivalent beam' method generaly agree with the reality. The application of the modification factors of Potts \& Addenbrooke assumes that no significant horizontal strain is induced in the building due to its axial stiffness. As a consequence, the categories of damage assessed by this method in the case study are completely out of reality.

The macro-model proposed by Lourenço (1996), based in two yield surfaces allowing to considering cracking and crushing effects, has predicted a crack pattern on dwellings in concordance with damage surveys. The obtained plastic strain distributions clearly show that the presence of openings in the facade has a notable importance in the onset of cracking. The predicted maximum crack opening agrees with damage surveys, thus showing the reliability and suitability of the presented numerical models. In general, the parts of buildings likely to be affected with more severity are found within the range of hogging.

Numerical linear elastic simulations of the structure provided similar results of damage than the approach of Burland and Wroth (1974). However, principal strains must be checked in zoned out of the influence of openings, which can amplify stresses in corners up to unrealistic values of strain.

In general, the 'equivalent beam' has been proved to be a useful tool in damage prediction due to tunneling which can be used in first stage of assessment of damage. Buildings likely to be more sensitive to tunnel subsidence can be successfully evaluated in more detail using the presented numerical FE Model.

\section{Acknowledgments}


The authors would like to thank the information provided by GISA (Gestió d'Infraestructures S.A.) and the Patronat Municipal de I'Habitatge de Barcelona. This research has received the financial support from the Ministerio de Educación y Ciencia through the research project SUBTIS (Study of the Sensitivity of Urban Buildings to Tunneling Induced Settlements, ref. num. BIA2009-13233), the ERDF (European Regional Development Fund) and the Col-legi d'Enginyers de Camins, Canals i Ports de Catalunya to carry out this research.
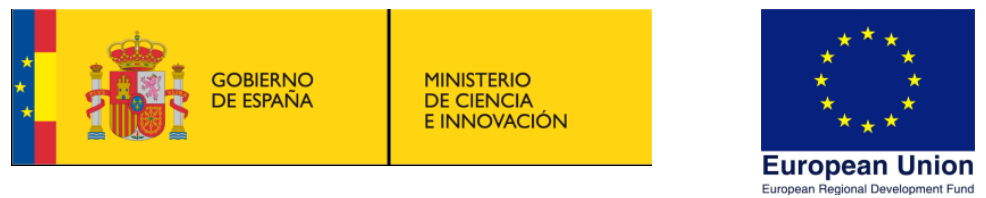

\section{$\underline{\text { References }}$}

ASTM INTERNATIONAL, (2010). ASTM C803 / C803M-03(2010) Standard Test Method for Penetration Resistance of Hardened Concrete. ASTM INTERNATIONAL, West Conshohocken, PA (USA).

ATTEWELL, P.B., YEATES, J. and SELBY, A.R. (1986) Soil movements induced by tunneling and their effects on pipelines and structures. Blackie Academic \& Professional (an Imprint of Chapman \& Hall).

BARBOSA, B. (2010) Análisis del comportamiento de un edificio de obra de fábrica sometido a asentamientos inducidos por la perforación de túneles. Barcelona: Universitat Politècnica de Catalunya.

BOSCARDIN, M.D. and CORDING, E.J. (1989) Building response to excavation-induced settlement. Journal of Geotech. Engineering, 115(1), pp. 1.

BURD, H.J., HOULSBY, G.T., AUGARDE, C.L. and LIU, G. (2000) Modeling tunneling-induced settlement of masonry buildings, 143 (Paper 11831), pp. 17-29

BURLAND, J.B. (2008) The assessment of the $r i$ sk of damage to buildings due to tunnelling and excavations. Jornada Técnica Payma Cotas: Movimiento de edificios inducidos por excavaciones: criterios de daño y gestión del riesgo, pp. 3.

BURLAND, J.B., BROMS, B. and DE MELLO, V.F.B. (1977) Behaviour of foundations and structures. State of Art. Report. Session 2. Proc. 9th Int. Conf. on Soil Mech. and Found. Eng., 2, pp. 495.

BURLAND, J.B., STANDING, J.R. and JARDINE, F.M. (2001) Building response to tunnelling: case studies from construction of the Jubilee Line Extension, London. London: Thomas Telford.

BURLAND, J.B. and WROTH, C.P., (1974). Settlement of buildings and associated damage. London: Pentech Press.

CAMÓs, C., (2011). A case study of damage on masonry buildings produced by tunneling induced settlements. Master Thesis, Universitat Politècnica de Catalunya .

DEVRIENDT, M., (2003). Assessing building response at King's X. Tunnels \& Tunnelling International, July 2003, pp. 24

DEULOFEU, C., SCHWARZ, H., MAIDL, U. and COMULADA, M., (2007). Data management for highly mechanized shield tunneling in the construction of the $L 9$ metro BCN. Underground Space - the 4th Dimension of Metropolises.

DIMMOCK, P.S. (2008) Effect of building stiffness on tunnelling-induced ground movement. Tunnelling and Underground Space Technology, 23(4), pp. 438-450.

EN 772-1 (2002), Methods of test for masonry units. Part 1: Determination of the compressive strength. European Committe for Standardization, Brussels, Belgium.

GATTI, M.C. and CASSANI, G. (2007). Ground loss control in EPB TBM tunnel excavation. Underground Space - the 4th Dimension of Metropolises, TUST.

GESTO, J.M. and GENS, A., (2008). Estimation of building damage due to tunneling: an analytical approach, pp. 141. Jornada Técnica de Movimientos de Edificios Inducidos por Excavaciones, Aula Payma Cotas

KYM, C.Y., BAE, G.J., HONG, S.W., PARK, C.H., MOON, H.K. and SHIN, H.S. (2001), Neural network based prediction of ground surface settlement due to tunneling. Computers and Geotechnics (2001) 28, 517-547

LOURENÇO, P.B. (1996) Computational strategies for masonry structures. PhD Thesis., University of Technology.

MAIR, R.J., TAYLOR, R.N. and BURLAND, J.B. (1996). Prediction of ground movements and assessment of risk of building damage due to bored tunneling. Proc. Int. Symp. on Geotechnical Aspects of Underground Construction in Soft Ground, , pp. 713.

MELCHERS, R.E. (1987) Structural reliability. Analysis and prediction. Ed. Ellis Horwood

MUZÁS LABAD, F. (2002). Consideraciones sobre la elección de coeficientes de balasto. Revista de Obras Públicas, no 3427, pp. 45.

O'REILLY, M.P. (1982) Settlements above tunnels in the United Kingdom - Their magnitude and prediction. Tunnelling ' 82 , London, 173-181.

PECK, R.B. (1969) Deep excavations and tunneling in soft ground. SOA Report, 7th Int. Conf. SM\&FE, State of the Art Volume, pp. 225.

POTTS, D.M. and ADDENBROOKE, T.I (1997), A structure's influence on tunneling-induced ground movements. Proc. Instn. Civ. Engrs. Geotech. Engng., (125), pp. 109

RANKIN, W.J. (1988) Ground movements resulting from urban tunneling; predictions and effects. Engineering Geology Special Publication, 5, pp. 79.

ROTS, J.G., INVERNIZZI, S. (2005) Prevision of settlement-induced cracking in historical building masonry facades. Structural Analysis of Historical Constructions, Taylor \& Francis Group.

SAMARASINGHE, W., PAGE, A.W. and HENDRY, A.W. (1982) A finite element model for the in plane behavior of brickwork. Proc. Inst. Civ. Eng., 71(2), pp. 171.

SANDOVAL, C., ROCA, P., BERNAT, E., and GIL, L. (2011) Testing and numerical modelling of buckling failure of masonry walls. Construction and building materials (25), pp. 4394-4402.

STANDING, J.R. (2008) Building Response to tunneling: the importance of monitoring. Jornada Técnica: Movimientos de edificios inducidos por excavaciones: criterios de daño y gestión del riesgo. Aula Payma Cotas 
TIMOSHENKO, S. (1957) Strength of materials Part I, D van Nostrand Co, Inc. London.

TNO (2005) Diana user's manual. Release 9. http://www.tnodiana.com. 


\section{APPENDIX A - Classification of building damage}

The classification of visible damage can be done according to the chart from Burland et al. (1977):

\begin{tabular}{ccccc}
\hline $\begin{array}{c}\text { Category } \\
\text { of } \\
\text { damage }\end{array}$ & $\begin{array}{c}\text { Normal degree } \\
\text { of severity }\end{array}$ & Typical damage & Affection & $\begin{array}{c}\text { Limiting tensile } \\
\text { strain } \\
\left(\varepsilon_{\text {lim }}\right)(\%)\end{array}$ \\
\hline 0 & Negligible & Hairline cracks less than $0.1 \mathrm{~mm}$ & Aesthetics & $0-0.050$ \\
\hline 1 & Very slight & Fine cracks up to $1 \mathrm{~mm}$ & Aesthetics & $0.050-0.075$ \\
\hline 2 & Slight & Cracks easily filled up to $5 \mathrm{~mm}$ & Aesthetics & $0.075-0.150$ \\
\hline 3 & Moderate & Cracks from 5 to $15 \mathrm{~mm}$. & Serviciability & $>0.300$ \\
\hline 4 & Severe & Extensive repair work. Cracks & Serviciability & 0.300 \\
\hline 5 & Very severe 15 to $25 \mathrm{~mm}$. & Stability & Partial or complete rebuilding. \\
Cracks $>$ 25mm. & &
\end{tabular}

\section{APPENDIX B - Prediction of ground movement}

Maximum settlement $\left(s_{\max }\right)$ can be estimated using the approach from Peck (1969), Attewell et al. (1986) and Rankin (1988), given by equation [1], where $V_{L}$ is the percentage of ground loss, $D$ the diameter of the tunnel section (in meters) and $i$ is the orthogonal distance in meters from tunnel axis to the inflection point of the settlement profile):

$S_{\max }=\frac{V_{L} \cdot D^{2}}{3.192 \cdot i}$

O'Reilly (1982) proposed the following expression for the location of inflection points $i$ of the settlement trough for a given tunnel depth $\left(z_{0}\right)$ :

$i=0.5 \cdot z_{0}$

For a tunnel with $D=12 \mathrm{~m}, z_{0}=15 \mathrm{~m}$ depth and $i=7.5 \mathrm{~m}$, the maximum settlement value is equal to $s_{\max }=$ $45 \mathrm{~mm}$.

The settlement $(s)$ profile in section A-A' (Figure B.1) can be well described by the Gaussian curve (equation [3]), where $y$ is the orthogonal distance from tunnel axis. However, what is of interest is the determination of settlement profile in section B-B', which corresponds to the facade of buildings. This wall is rotated $\theta=26^{\circ}$ from the reference section A-A'. Moreover, tunnel track (dashed line) in this zone is curved. Therefore, settlement profile in B-B' will not follow exactly the shape of a Gaussian probability density function. Its shape will be in the transition from a density to a cumulative Gaussian functions. However, for small rotations respect the transverse section of the tunnel track, the shape will be very similar to a probability density function. For this reason, one can imagine a group of lines parallel to the tunnel track, thus joining points subjected to equal settlement. Then, if a settlement is calculated in section $A-A^{\prime}$, the lecture can be transferred by simple trigonometry to section B-B' (for instance, between points $a-b$, assuming nearly null curvature between the two sections (tunnel track radius $=300 \mathrm{~m})$.

$$
s=s_{\max } \exp \left(\frac{-m^{2}}{2 i^{2}}\right) \quad \text { where } m=\frac{y}{\cos \theta}
$$




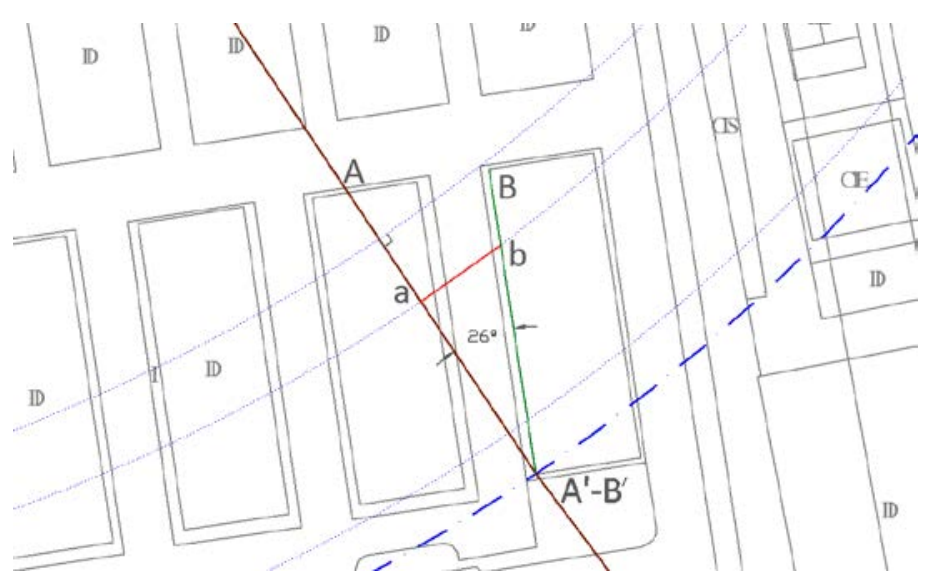

Figure B.1 Projection of monitoring points on a reference section

Horizontal movements in ground $(u)$ in the transverse section to the tunnel can be estimated with the expression [4] given by O'Reilly (1982). Horizontal strain $\left(\varepsilon_{h}\right)$ can be simply calculated by derivation of $u$ respect to $y$.

$u=\frac{s \cdot y}{z_{0}}$

\section{APPENDIX C - Assessment of building damage using the equivalent beam method}

- Burland \& Wroth (1974) and Boscardin \& Cording (1989) approach

Bending and shear strains on the equivalent beam under deflection are given by equations [5] and [6], where $\Delta / L$ is the deflection ratio, $L$ is the distance between two reference points and $\Delta$ is the relative deflection between these two points, $t$ is the height of the neutral axis, $\varepsilon_{b \max }$ and $\varepsilon_{d \max }$ are the maximum tensile strain due to bending and shearing respectively, $d$ is the height of the fiber were strains are calculated, $H$ is the beam depth, I the inertia per unit length and $E / G$ is the ratio between the elastic and shear modulus of the material.

$\frac{\Delta}{L}=\left(\frac{L}{12 t}+\frac{3 l}{2 d L H} \frac{E}{G}\right) \varepsilon_{b \max }$

$\frac{\Delta}{L}=\left(1+\frac{H L^{2}}{18 I} \frac{G}{E}\right) \varepsilon_{d \max }$

Independent beams are considered for sagging and hogging. Their lengths are $L_{s a g}=8.2 \mathrm{~m}$ and $L_{\text {hog }}=38.3 \mathrm{~m}$. Beam depth is equal to $H=3 \mathrm{~m}$, neutral axis is located at half depth $\left(t_{s a g}=1.5 \mathrm{~m}\right)$ for sagging and at top fiber for hogging $\left(t_{\text {hog }}=3 \mathrm{~m}\right)$, strains are calculated in the most critical fiber from neutral axis so that $d=t$, inertia per unit length $(I)$ is equal to $2.25 \mathrm{~m}^{4} / \mathrm{m}$ and finally, elastic/shearing modulus ratio is $E / G=2.5$, typical for masonry structures.

The influence of horizontal tensile strain from ground $\left(\varepsilon_{h}\right)$ can be introduced by Boscardin \& Cording (1989) expressions, assuming that the deflected beam is subjected to uniform extension over its full width (out of plane). The resultant extreme fiber strains in bending and shearing ( $\varepsilon_{b r}$ and $\varepsilon_{d r}$ ) are given by expressions [7] and [8], where $v$ is the Poisson's ratio.

$\varepsilon_{b r}=\varepsilon_{b \max }+\varepsilon_{h}$

$\varepsilon_{d r}=\varepsilon_{h}\left(\frac{1-v}{2}\right)+\sqrt{\varepsilon_{h}^{2}\left(\frac{1+v}{2}\right)^{2}+\varepsilon_{d \max }^{2}}$ 
The purpose of this parametric study was to calculate the modification factors $(M)$ (expressions [9] and [10]) to apply to the deflection ratios $(D R$ or $\Delta / L)$ and to horizontal strains coming from ground $\left(\varepsilon_{h}\right)$ in order to consider the global stiffness that both building and soil provide. A modification factor of 1 (or greater) represents fully flexible behavior, since the building follows the greenfield settlement profile, whereas a modification factor close to zero represents very stiff behavior (the deflection ratio of the building is almost zero). In the following expressions, superscript ' $g$ ' refers to greenfield conditions, ' $c$ ' refers to compressive strains and ' $t$ ' refers to tensile.

$$
\begin{aligned}
& M^{\text {DRsag }}=\frac{(\Delta / L)_{s a g}}{\left(\Delta / L^{g}\right)_{s a g}} ; M^{D R h o g}=\frac{(\Delta / L)_{h o g}}{\left(\Delta / L^{g}\right)_{h o g}} \\
& M^{\varepsilon_{h c}}=\frac{\varepsilon_{h c}}{\varepsilon_{h c}^{g}} ; M^{\varepsilon_{h t}}=\frac{\varepsilon_{h t}}{\varepsilon_{h t}^{g}}
\end{aligned}
$$

Two measures of relative stiffness were introduced: the relative bending stiffness $\left(\rho^{*}\right)$ and the relative axial stiffness $\left(\alpha^{*}\right)$, defined as:

$$
\alpha^{*}=\frac{E A}{E_{s} B} \quad \text { and } \rho^{*}=\frac{E I}{E_{s} B^{4}}
$$

Where:

- $\quad B$ is the half-length of the beam $(=46.5 \mathrm{~m} / 2=23.25 \mathrm{~m})$

- $\quad E$ is the modulus of elasticity of the beam, taken as $2500 \mathrm{MPa}$ in first approximation.

- $A$ is the cross-section area per unit length (out of plane direction) equal to $3 \mathrm{~m}^{2} / \mathrm{m}$.

- $\quad l$ is the inertia per unit length equal to $2.25 \mathrm{~m}^{4} / \mathrm{m}$ (considering a wall $1 \mathrm{~m}$ wide).

- $\quad E_{s}$ is a representative soil stiffness. According to the type of ground with grained sand and clay and silts, typical from a river delta (Calavera, 2000), the subgrade reaction modulus of ground can be taken as $0.09 \mathrm{~N} / \mathrm{mm}^{3}$. Assuming a $30 \mathrm{~cm}$ width continuous foundation, $E_{s}$ can be estimated in $27 \mathrm{MPa}$.

Then, the relative stiffness measures are $\alpha^{*}=11.9$ and $\rho^{*}=0.0007 \frac{1}{m}$.

The design curves for horizontal strain modification factors for a given tunnel eccentricity $(e /(2 B))$, where $e$ is the difference of distance between tunnel axis and building centerline and $B$ is the building half-length, can be find in Potts \& Addenbrooke (1997). The eccentricity in this case is 0.5 , since the tunnel is located under the corner of the set of buildings. The resulting modification factors for these relative stiffness measures are $M^{\text {DRsag }} \approx 0.5, M^{\text {DRhog }} \approx 1.2, M^{\varepsilon_{h c}} \approx 0.01$ and $M^{\varepsilon_{h t}} \approx 0.01$.

\section{APPENDIX D - Notation and units used in this paper}

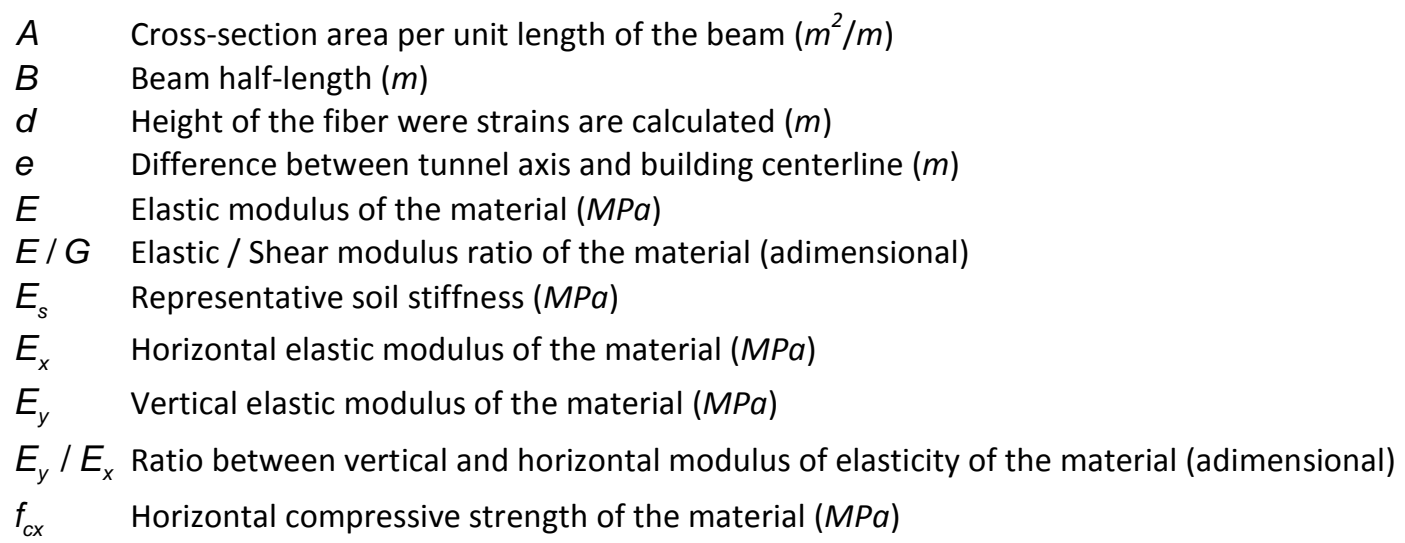


$f_{c y} \quad$ Vertical compressive strength of the material $(\mathrm{MPa})$

$f_{c y} / f_{c x}$ Ratio between vertical and horizontal compressive strength of the material (adimensional)

$f_{t x} \quad$ Horizontal tensile strength of the material $(\mathrm{MPa})$

$f_{t y} \quad$ Vertical tensile strength of the material $(\mathrm{MPa})$

$G \quad$ Shear modulus of the material $(\mathrm{MPa})$

$H \quad$ Beam depth $(m)$

I Inertia per unit length $\left(\mathrm{m}^{3} / \mathrm{m}\right)$

$i \quad$ Value of orthogonal distance of the point of inflection from tunnel axis $(m)$

$K \quad$ Trough width parameter (adimensional)

$K_{s} \quad$ Compression stiffness of non-linear springs $(\mathrm{N} / \mathrm{mm})$

$L \quad$ Distance between two reference points $(m)$

$M \quad$ Modification factors of Potts \& Addenbrooke (adimensional)

$M_{\text {hogg }}^{D R} \quad$ Modification factor of Potts \& Addenbrooke to be applied on the deflec. ratio of hogg. (adim.)

$M_{\text {sag }}^{D R} \quad$ Modification factor of Potts \& Addenbrooke to be applied on the deflec. ratio of sagg. (adim.)

$M^{\varepsilon_{h c}} \quad$ Modif. factor of Potts \& Addenbrooke to be applied on the compressive ground strain (adim.)

$M^{\varepsilon_{h t}} \quad$ Modif. factor of Potts \& Addenbrooke to be applied on the tensile ground strain (adim.)

$S \quad$ Settlement $(\mathrm{mm})$

$S_{\max } \quad$ Maximum settlement $(\mathrm{mm})$

$t \quad$ Position of neutral axis $(m)$

$u \quad$ Horizontal displacements of ground surface $(\mathrm{mm})$

$y \quad$ Orthogonal distance from tunnel axis $(m)$

$z_{0} \quad$ Tunnel depth from surface to tunnel axis $(m)$

$\alpha$ * Relative axial stiffness of the beam (adimensional)

$\Delta \quad$ Relative deflection, displac. of a point relative to the line connecting two refer. points $(\mathrm{mm})$

$\Delta / L \quad$ Deflection ratio (adimensional)

$\varepsilon_{b \max } \quad$ Maximum tensile strain in the equivalent beam due to bending (adimensional)

$\varepsilon_{b r} \quad$ Resultant extreme fiber strain in bending, accounting for ground strain (adimensional)

$\varepsilon_{d \max } \quad$ Maximum tensile strain in the equivalent beam due to shearing (adimensional)

$\varepsilon_{d r} \quad$ Resultant extreme fiber strain in shearing, accounting for ground strain (adimensional)

$\varepsilon_{h} \quad$ Horizontal ground strain at surface level (adimensional)

$\varepsilon_{h \text { mean }}$ Mean value of horizontal ground strain at surface level (adimensional)

$\varepsilon_{p 1} \quad$ Plastic strains (adimensional)

$\varepsilon_{x} \quad$ Principal strains (adimensional)

$v \quad$ Poisson's ratio (adimensional)

$\rho^{*} \quad$ Relative bending stiffness of the beam $(1 / \mathrm{m})$ 